\title{
Protection system of hydraulic drive of road construction machinery
}

\author{
Nikolay Fomenko ${ }^{1}$, Oleg Burlachenko ${ }^{1}$, and Maxim Ivanov, ${ }^{1, *}$ \\ ${ }^{1}$ Volgograd State Technical University, Department of Construction Production Technology, Avenue V.I. Lenin, 28, 400005, Volgograd, \\ Russia
}

\begin{abstract}
Tendencies of development of ways of protection of a hydraulic drive of vehicles from unauthorized emission of working liquid at destruction of high pressure holes are analyzed. The analysis of work of traction vehicles, detects the reasons at which there is a destruction of high pressure hoses of hydraulic system and the emission in the atmosphere of working liquid that violate environmental safety. Technical solution is proposed for elimination of negative consequences of destruction of high pressure hoses, which author's rights are protected by the patent. Its essence is, that the locking device is further supplied with a rod with the axial through channel, which will allow a plunger in case of a gap of head pressure hoses reliably to block radial holes in a rod, to provide that high reliability of the overlap of supply of working liquid in head pressure hoses in case of their destruction and effective protection of hydraulic drive against unauthorized emission of working liquid.
\end{abstract}

\section{Introduction}

Researches show that at damage of high pressure hoses of hydraulic machines [1-11] is released into the atmosphere the significant amount of working liquid, equal to nearly a volume of a hydraulic tank. It leads to deterioration in an ecological situation. Despite the taken measures for restriction of pressure in high pressure hoses and decreasing upon them cyclic loadings, the problem of search of technical solutions, caused by the improvement of the design elements of hydraulic system, for example, the flexible of high pressure hoses [12], or new methods and the principles of protection of hydraulic drive [13-23] remains urgent.

Operational properties of a prototype [13], as the closest to an effective objective, have a low efficiency of operation of the locking device of protection system of hydraulic drive. It is caused by the fact, that in the time of the message of an input cavity through radial holes of a plunger and the channel drain union with the line of discharge, pressure in the input cavity decreases and because of oscillatory process of a plunger and prevents the overlap of the channel drain union. The arising fluctuations of the locking regulating element - of plunger are followed by intensive blows of the valve about a saddle and fluctuations of pressure in system that is a cause of wear and losses of tightness of the valve. At the same time, time of overlapping of the channel of the output fitting, reduces speed of the locking device.

To the disadvantage of this protection system can be attributed not reliable overlapping of a stream of working liquid by conical valve, contacting to a saddle, which requires for close contact of pairing considerable spring force, that causes stiff operation of the valve locking devices, wear of the valve, decrease in the operating reliability of the device and environmental safety of the use of hydraulic drive machines. The disadvantage of this protection system is also what closed not compressible the volume of working liquid, formed between the plunger at the end of his stroke and an emphasis, prevents reliable the overlap of the channel of the output fitting and provokes leak of working liquid in the damaged hydraulic line at operation of the locking device, leads to growth of losses of working liquid.

Besides, the disadvantage of this protection system of hydraulic drive is that, is not regulated the threshold of operation of the locking device, determined by differential pressure between input and output cavities. It causes to low universality locking device for installation in protection system of hydraulic drive of various machines.

\section{Main part}

System is intended for protecting hydraulic drives of machines from unauthorized discharge of working fluid from hydraulic system. System includes hydraulic tank, pump connected by pressure hydraulic line with hydraulic drive through distributor, and locking device including housing with inlet and outlet cavities, inlet, outlet and drain unions with channels and stop. Locking device is equipped with a rod with axial through channel, one end rigidly fixed in the stop. In the axial through channel of the rod there are radial holes, thread and adjustment screw for adjusting actuation threshold of the locking device. Other end of rod is located in the axial

\footnotetext{
Corresponding author: clevermax18@mail.ru
} 
channel of plunger with possibility of piston displacement along the rod. System is equipped with check valve installed on the pressure hydraulic line between the pump and a locking device, two shutoff valves and hydraulic lock, the control cavity of which is connected with drain union with the housing channel and through one shutoff valve is connected to the drain hydraulic line, input cavity of hydraulic lock is connected to pressure hydraulic line between the pump and check valve and an outlet cavity of hydraulic lock is connected to drain hydraulic line. Input cavity of the locking device housing is connected to drain hydraulic line through the inlet connection pipe with channel and other shutoff valve. Effect: higher operational efficiency, response time and universality of the locking device.

The essence of the proposed technical solution consists is that the adjusting screw, installed in the axial channel of a rod from an emphasis, allows to change the section of the radial holes, through passage reporting input and output cavities through the axial channel of a rod and, as a result, by throttling of a stream of working liquid to regulate differential pressure, between output and input cavities, the defining threshold of operation of the locking device. It allows to carry out control of a threshold of operation of the locking device excluding false operation, connected with pressure decline in an output cavity of the locking device, or when draining of working liquid in the neutral position of the control valve spool, or idle operating mode of hydraulic drive. Settings of a threshold of operation of the locking device provide high universality of the locking device at installation in systems of the protection of hydraulic drive of various machines.

The proposed protection system is equipped with the hydraulic lock and two shutoff valves, which allow to provide constancy pressure in the input cavity at destruction head hoses of power hydraulic drive, thus draining the working liquid from the input cavity does not occur, since the channel drain union locking device is connected with the deaf administering of a cavity of the hydraulic lock and on the drain hydraulic line closed shutoff valve. Discharge in a hydrotank of the working liquid pumped is carried through the opening hydraulic lock the operating signal in the form of liquid pressure in an input cavity of the locking device appearing when moving a plunger to extreme right situation at destruction of head pressure hoses. At the same time the check valve and the shutoff valve lock working liquid on an inlet of the locking device and exclude an overflowing it from an input cavity to pressure and drain hydraulic lines at the begun discharge of the working liquid pumped from the pressure hydraulic line through input and output cavities of the hydraulic lock in a hydrotank.

Thus, the input cavity will be blocked on an inlet by the check valve, at the exit the plunger, blocking radial holes on a rod, and the channel drain union is reported from the deaf administering cavity. Therefore, in an input cavity of the locking device will be supported by the plunger with a spring the constant pressure of the liquid, which has appeared in the closed volume of the input cavity. Constant pressure in the input closed cavity of the case excludes fluctuations of a plunger, allows to hold constantly blocked radial holes of a rod and opened the hydraulic lock, which provides the draining of liquid in a hydrotank at a rupture of head pressure hoses. It significantly increases speed of the locking device and effectiveness of the protection system of hydraulic drive.

The protection system of hydraulic drive works as follows (fig. 1). In the operating state systems of protection shutoff valves 17 and 26 are closed. In a static state protection system of hydraulic drive, that is in the neutral position spools of the distributor 7, the working liquid is supplied by pump 2 through the check valve 5 , the input channel of the fitting 10 in an input cavity A of the housing 9 and further comes on channel $\mathrm{C}$ on the inside of the rod 19 and his radial holes 22 to an output cavity of B, and through the output channel of the fitting 11 to the entrance distributor 7. In this position of the spools of the distributor 7 is drained of working liquid to the drain hydraulic line 8 through his overflow valves. Pressure of working liquid in cavities of $A$ and $B$ at the same time almost identical. The plunger 15 is supported a spring 14 and is located in the extreme left position, at the same time radial holes 22 of rods 19 are open and report among themselves through channel $\mathrm{C}$ of a rod 19 cavities to A and B locking devices 6 .

When moving the spools of the distributor 7 the position of the rising, the working liquid is supplied by pump 2 through the check valve 5 , the input channel of the fitting 10 in an input cavity A of the housing 9 and further comes on channel $\mathrm{C}$ of the rod 19 and his radial holes 22 in the output cavity B, and through the output channel of fitting 11 is fed to the entrance distributor 7 , which feeds the working pressure of hydraulic drive 3. The liquid stream at the same time creates differential pressure between cavities of A and B locking devices, the backwater from which on the plunger 15 is compensated by a spring 14 . The edges of radial holes 22 turned to an end face of a burt 20, spaced from the right end face of a plunger 15 at sufficient distance of e, at which in the regular working condition of a hydraulic system there is no their closing with a cylindrical surface of axial channel 16 of a plunger, and there is also no opening of the channel drain union 12 of the left end face of a plunger, as the edge of the channel drain union is located at the same distance of e from an end face of the input fitting 10 .

At a rupture of head pressure hoses of supply of hydraulic drive pressure in an output cavity of $B$ significantly decreases and, because of the increased stream of working liquid from an output cavity of B, there is considerable differential pressure in cavities of $\mathrm{A}$ and $\mathrm{B}$.

By effort from differential pressure in cavities of A and B case 9 the plunger 15, overcoming resistance of a spring 14 , moves to the right against the stop 13, closing the cylindrical surface of axial channel 16 radial holes 22 with the overlap equal to the distance $\mathrm{S}$ from edges of radial holes to the end face of the burt 20 of the rod 19. At the same time supply of working liquid from an input cavity of A in output cavity of B stops. Considerable overlap of radial holes 22 of surface of axial channel 16 of plunger 15 excludes infiltration of working liquid 
from an input cavity of A in output cavity B case 9 through a gap between a rod 19 and axial channel 16 of a plunger because of big hydraulic resistance in a gap.

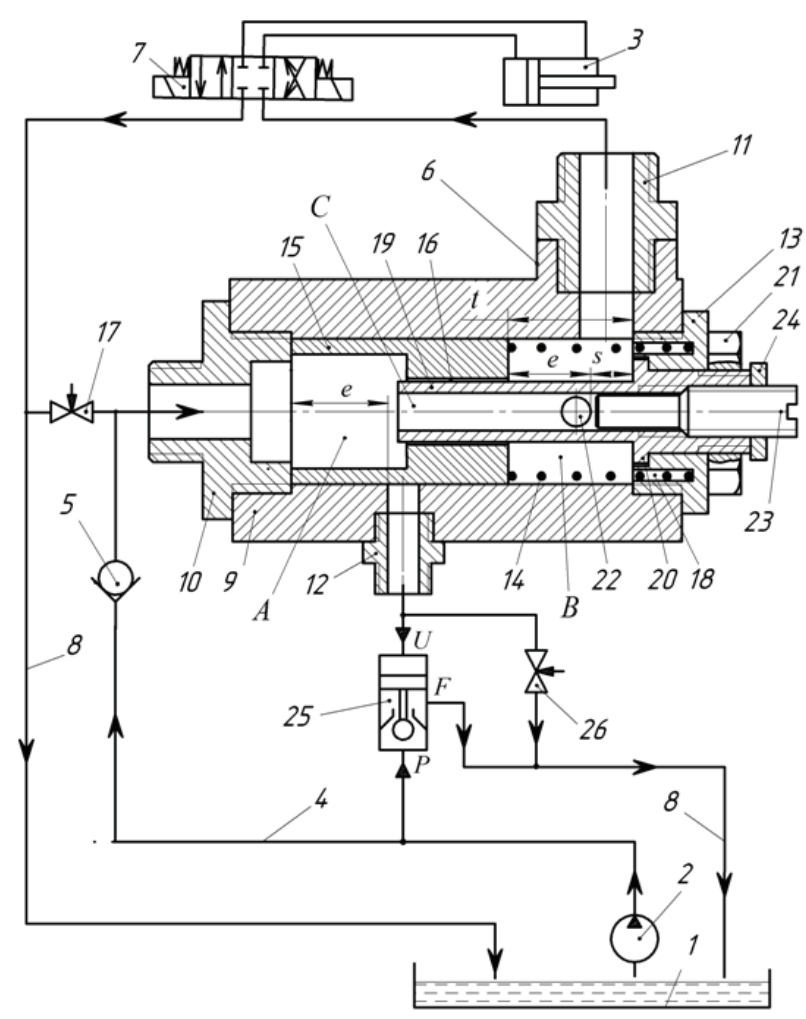

Fig.1. Protection system of hydraulic drive road construction machinery

In an emergency condition of a hydraulic system at a rupture of hoses of power hydraulic drive the plunger 15 under the influence of differential pressure moves in extreme right position on the distance of his full speed $t$ and its left end face opens of the channel drain union 12 by which at the closed valve 26 pressure of working liquid as the hydraulic operating signal, is transmitted to the deaf control cavity U hydraulic lock 25 . At the same time the hydraulic lock opens and through his input $\mathrm{P}$ and output $\mathrm{F}$ is ignored working liquid from the discharge hydraulic line 4 of the pump 2 to drain into the drain hydraulic line 8 and pressure in the pressure hydraulic line from the pump to the check valve 6 considerably decreases. The pressure drop in the pressure hydraulic line can cause the return outflow of working liquid from cavity A to the pump 2 under action on a plunger 15 the compressed springs 14 when the plunger at destruction of head pressure hoses settles down in extreme right position and rests against an stop 13. However, the check valve 5 excludes the return outflow of liquid to the pump from a cavity A case 9 of the locking device 6 .

In an emergency condition of a hydraulic system at a rupture of hoses of power the cavity A locking devices is closed, as the valve 17 her communications with the drain hydraulic line 8 is closed, the holes 22, reporting cavity A with an output cavity of B are blocked by a surface of axial channel 16 of a plunger 15, the check valve 5 doesn't pass working liquid from cavity A to the pump 2, and the drain union 12 with the channel is reported from the deaf administering cavity $U$ hydraulic lock 25. In such condition of the locking device 6 pressure in a cavity of A will be constant and the plunger 15 at an emergency rupture of head pressure hoses will remain not movably in the position of full overlapping of radial holes 22 the surface of axial channel 16 of a plunger.

Constant pressure in the input closed cavity A case 10 of the locking device 6 excludes fluctuations of a plunger 15, allows to hold constantly blocked radial holes 22 and opened the hydraulic lock 25 which provides discharge of liquid in a hydrotank 1 at a rupture of head pressure hoses.

For restoration of an initial condition of the protection system after elimination of a emergency condition of the protection system of hydraulic drive, at the switched-off pump 2 open shutoff valves 17 and 26 . At the same time pressure in an input cavity A housing 9 of the locking device 6 and the control cavity $U$ hydraulic lock 25 decreases, under the influence of a spring the 14 plunger 15 moves to the left to an initial state. The working liquid from a cavity of $\mathrm{A}$ is forced out by a plunger 15 through the valve 17 , and from the control cavity $U$ hydraulic lock 25 through the valve 26 to the drain hydraulic line 8 and further in a hydrotank 1 .

The threshold of operation of the locking device determined by differential pressure between his output B and input $\mathrm{A}$ cavities is regulated by the throttling of a stream of working liquid by means of the adjusting screw 23 changing the flow section of the holes 22 . The screw 23 performs exact tuning of a threshold of operation of the locking device 6 , his sensitivity for differential pressure between output $\mathrm{A}$ and input $\mathrm{B}$ cavities that allow to achieve its maximum speed, exclude its false operations and provide high universality of application him in protection system of hydraulic drive of various machines.

\section{Conclusions}

Thus, the proposed technical solution allows to increase the efficiency of protection system of hydraulic drive against unauthorized emission of working liquid from hydraulic system, to provide speed of the locking device, operational reliability and an environmental safety of use of hydraulic drive of working bodies of machines.

\section{References}

1. S.A. Astapchik, V.S. Golubev, A.G. Maklakov, Laser technology in the mechanical engineering and metals industries. (Minsk: Belorus. science, 2008)

2. V.N. Fomenko, Development of systems of protection of hydraulic actuators of mechanisms of a hinge plate of traction and special transport cars. (Diss. Candidate of Technical Sciences. Volgograd, 2000) 
3. N.G. Dyurgerov, Technological methods of recovery and improve the wearing capacity of machine parts: Tutorial, Part. (Donetsk State Technical University, Rostov-on-Don, 2006)

4. A. Harnoy, H. Rachoor, Modeling of dynamic friction in lubricated line contacts for precise motion control. Tribology Trans. 601 - 612 (1995)

5. A. Harnoy, B. Friedlan, Dynamic friction model of lubricated surfaces for precise motion control. Tribology conf. New Orleans. 24 - 27 (1993)

6. N.A. Kovalev, Applied mechanics. (M.: Higher school, 2000)

7. I.M. Fedorchenko, I.N. Frantsevich, I.D. Radomyselsky, Powder metallurgy. Materials, technology, properties, fields of application: reference book. (Kiev: Naukova thought, 1985)

8. D.N. Garkunov, Tribotechnology: design, manufacture and operation of the machine. (Publishing House of the ICCA, Moscow, 2002)

9. F. Findik, Investigation of explosive welding parameters and their effects on microhardness and shear strength. 659-664 (2003)

10. Yu.G. Dorofeev [etc.], Industrial technology of hot pressing of powder products. (M.: Metallurgy, 1990)

11. V.B. Ilitsky, V.V. Mikityansky, L.M. Serdyuk, Machine-tool accessories, Design and Technology software operating properties. (Engineering, Moscow, 1989)

12. N.A. Fomenko, V.I. Bogdanov, V.N. Fomenko, The high pressure pipeline. Patent RF, no. RU 25111926 C 2 F 15 B 20/00, F 16 L 11/20

13. N.A. Fomenko, V.I. Perel'miter, V.N. Fomenko, System of Hydraulic Control Protection. Patent RF, no. RU 15763 U 17 F 15 B 21/00

14. V.N. Fomenko, V.I. Perel'miter, N.A. Fomenko, V.P. Shevchuk, Hydraulic System. Patent RF, no. RU 15764 U 17 F 15 B 21/00

15. N.A. Fomenko, S.V. Dubinskiy, G.I. Golobuta, G.P. Lyshko, System of Hydraulic Control Protection. Patent RF, no. SU 1813937 A 1 F 15 B 20/00

16. I.P. Ksenevich, V.A. Nasirov, Device of emergency protection of the vehicle. Application for the invention No. 4820466/06 (048212) of 01.03.91

17. V.I. Perel'miter, Hydraulic system. Patent RF, no. SU 1822471 A 3 F 15 B 20/00

18. A.M. Dalsky, B.M. Bazrov, A.S. Vasiliev, Technological heredity in engineering production. (Publishing house of the Moscow Aviation Institute, Moscow, 2000)

19. V. A. Altman [etc.], Influence of an alloying on physico-mechanical interaction and frictional characteristics of powder materials with solid lubricants, Powder metallurgy, 2, 67-69 (1980)

20. N.A. Fomenko, V.I. Bogdanov, S.V. Alexikov, V.N. Fomenko, S.A. Bogdanov. System of protection of hydraulic actuator. Patent RF, no. RU 2571240 C 1 F 15 B 20/00

21. Yu. K. Bobkov, V.P. Shevchuk, V.G. Chernyshev. Method of protection of a hydraulic system. Patent RF, no. SU 1550255 A 1 F 15 B 20/00

22. V.I. Bogdanov, N.A. Fomenko, O.V. Burlachenko, S.V. Alexikov, S.A. Bogdanov, V.N. Fomenko. System of protection of hydraulic actuator. Patent RF, no. RU 2579531 C 1 F 15 B 20/00

23. Yu.P. Serdobintsev, O.V. Burlachenko, A.G. Skhirtladze. Improving of the quality of functioning of technological equipment. (A monograph, Staryi Oskol, TNT Publ., 2010) 